\title{
Evaluation of a Point-of-Use Electrocoagulation System for Arsenic Removal
}

\author{
Megan K. Alferness \\ Senior, Department of Civil Engineering \\ Santa Clara University
}

\author{
Alexandria R. Casares \\ Senior, Department of Civil Engineering \\ Santa Clara University
}

\author{
Steven C. Chiesa* \\ Associate Professor \\ Department of Civil Engineering \\ Santa Clara University \\ *Correspondence: $\underline{\text { schiesa@ scu.edu }}$
}

\begin{abstract}
A point-of-use prototype electrocoagulation treatment system was designed and evaluated for its ability to remove arsenic from a synthetic groundwater. The system was comprised of an electrocoagulation reactor providing batch treatment, a rechargeable battery power source, an electrical monitoring and control module, and a granular media filter. The control module and the filter underdrain system were designed to improve user convenience. The system was able to consistently reduce arsenic concentrations to below 20 $\mu \mathrm{g} / \mathrm{L}$. Effluent soluble arsenic concentrations under $10 \mu \mathrm{g} / \mathrm{L}$ were deemed possible with enhanced effluent suspended solids removal techniques. Arsenic removal was found to be a function of the initial arsenic concentration and the cumulative charge dosage as measured in coulombs per liter of water treated. The steel plate size used in the electrocoagulation module influenced the current draw and the overall electrical efficiency of the system. The monitoring and control module allowed the system to produce up to 100 liters of treated water daily on a single battery charge and would automatically control charge and iron dosage. The point-of-use system was capable of meeting household potable demands for water where other treatment options are limited.
\end{abstract}

Index Terms - arsenic; electrocoagulation; point-of-use; prototype

\section{INTRODUCTION}

Arsenic contamination in groundwater is a problem affecting over 225 million people globally in approximately 105 countries $^{1,2}$. Areas experiencing elevated groundwater arsenic levels include North America, South America, South Asia, Central Asia, and Australia. Potential human health issues associated with prolonged potable use of arsenic-containing water include skin damage, circulatory system problems, neurological effects, and increased cancer risks ${ }^{3}$. As a result of these potential impacts, the United States Environmental Protection Agency (USEPA) and the World Health Organization (WHO) have established maximum acceptable levels of arsenic in drinking water at $10 \mu \mathrm{g} / \mathrm{L}$. Other agencies and countries around the world have locally set acceptable arsenic levels as high as $50 \mu \mathrm{g} / \mathrm{L}^{4}$.

A number of technologies have been identified for removing inorganic arsenic from groundwaters that potentially serve as sources of potable water. The four most common 
technologies include ion exchange, precipitation, coagulation/adsorption, and membrane treatment systems ${ }^{4-9}$. These processes have been shown to be capable of producing high quality finished water but most require expensive resins, replaceable adsorption media, and/or chemicals to sustain effective, long-term operation. Systems utilizing fixed adsorption media in contact columns have also been plagued by clogging when untreated waters contain elevated concentrations of reduced iron. Arsenic removal from groundwater using an electrocoagulation (EC)-based process technology has been recently demonstrated as a viable approach to potable water production as it appears to provide effective treatment over a wide range of conditions while minimizing many of the limitations and water chemistry-based site-specific issues associated with other technologies ${ }^{10,11}$. The EC technology has been shown capable of providing treatment either at laboratory scale ${ }^{12,13}$ or in small communal systems ${ }^{14}$. The goal of this project was to design and operationally evaluate a small point-of-use arsenic removal system providing arsenic removal based on EC technology. Experimentation revolved around treating the type of arsenic-contaminated groundwaters commonly encountered in South Asia where arsenic levels range between 100 and $300 \mu \mathrm{g} / \mathrm{L}$. EC-based treatment was chosen because of its potential to produce a high-quality treated water in a relatively simple, resource-frugal manner ${ }^{12,15}$. Because the prototype system was designed for application in the rural areas of developing nations, relevant design and operating constraints were identified through communications with the head of a non-governmental agency (NGO) providing services in south Asia. The primary limiting factor was identified as being the available electrical power supply. The final prototype system tested was designed to operate using a small 6.0 volt direct current (VDC) rechargeable battery while producing an effluent that could potentially satisfy a $10 \mu \mathrm{g} / \mathrm{L}$ arsenic limit.

\section{METHODS}

The test treatment system was comprised of four integrated elements: an EC reactor, an electrical power source, a control module for electrical current monitoring and dosage control, and a granular media filter. Figure 1 provides a schematic representation of how these individual elements were configured for evaluating system performance. 
International Journal for Service Learning in Engineering, Humanitarian Engineering and Social Entrepreneurship

Vol. 11, No. 1, pp. 51-66, Spring 2016

ISSN 1555-9033

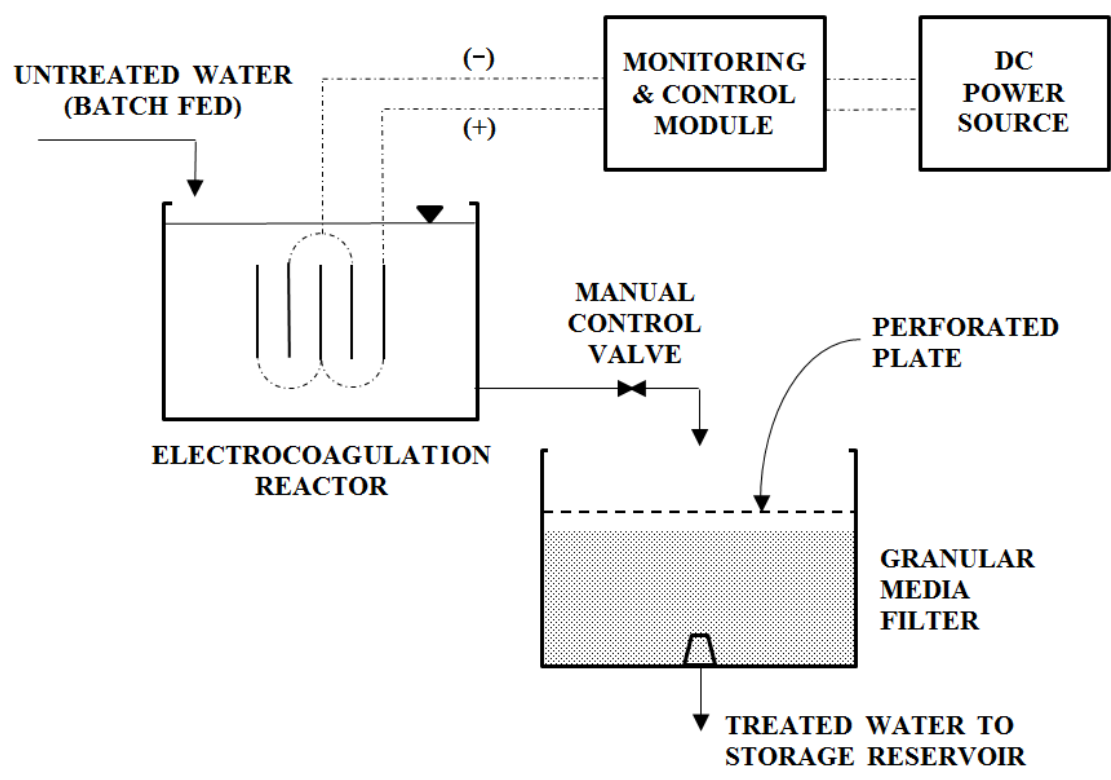

FIGURE 1

TREATMENT SYSTEM SCHEMATIC DIAGRAM

The test system was fabricated using products and materials available in the general South Asia region with cost, physical size, and weight minimization being primary constraints. Plastic parts were used wherever possible to minimize corrosion problems. A commercial multimeter was used on occasion to help verify electrical operation. Batch treatment test cycles using the prototype system were run at least twice for each set of operating conditions to verify system performance. Details for each system element are provided in the following paragraphs.

\section{EC Reactor}

The EC reactor employed a 13.2 L liquid volume batch-fed plastic bucket as the containment vessel. This system liquid volume provided $5 \mathrm{~cm}$ of freeboard. The EC module was fabricated from five parallel sheets of $3.175 \mathrm{~mm}$ thick mild carbon steel plate. Two plate sizes were selected for evaluation. Both $10 \mathrm{~cm} \times 10 \mathrm{~cm}$ and $15 \mathrm{~cm} \times 15 \mathrm{~cm}$ plates were tested using the same reactor vessel and compared for their ability to reduce arsenic concentrations down to target effluent levels as a function of time and cumulative power draw. Before use, exposed plate surfaces were conditioned by abrading them with coarse sand paper. All plates were separated by a uniform distance using plastic block spacers and nylon threaded rods and nuts. The center plate and two extreme outer plates served as anodes with the other two plates serving as cathodes. The five-plate EC module was suspended mid-depth using a piece of $12 \mathrm{~mm}$ diameter Schedule $40 \mathrm{PVC}$ pipe and plastic support chain. This configuration allowed for rapid assembly and disassembly. A terminal block (with jumpers) attached to the outside top of the container was used to distribute electrical power to the individual plates and provide for the needed current flow. Wires from the terminal block were connected to the plates using 10 gauge insulated, solid copper wire and liquid electrical tape-based watertight connections.

Several experimental runs were conducted with supplemental mechanical mixing to assess the impact of increased turbulence on system performance. Mechanical mixing was provided using a magnetic stirrer located directly under the center of the EC reactor and a Teflon coated 
International Journal for Service Learning in Engineering, Humanitarian Engineering and Social Entrepreneurship Vol. 11, No. 1, pp. 51-66, Spring 2016

ISSN 1555-9033

"floating" stir bar placed on the center bottom of the reactor. The mechanical mixing energy intensity was set to ensure more uniform suspension of the internally generated hydrous ferric oxide (HFO) particles materials in the tank. When employed, the supplemental mechanical mixing was maintained from the beginning to end of the otherwise standard reaction cycle.

\section{Power Sources}

The EC module was designed to operate with a 6.0 to $7.0 \mathrm{VDC}$ power source. Two alternative power sources were used when evaluating system operation. A Mastech HY3005F-3 Triple Linear DC regulated power supply was used initially to establish an operational baseline for comparing electrocoagulation system performance under controlled conditions. Subsequent experimental runs employed a rechargeable battery as the sole power source. The battery was rated at 6.0 volts with a power storage capacity of at least 4.5 amp-hours and was recharged repeatedly during the course of the experimental work with no apparent loss in performance. When using $10 \mathrm{~cm} \times 10 \mathrm{~cm}$ plates in the EC module, both power sources provided the target operating voltage while maintaining the same, constant electrical current. The regulated DC power supply was used for all experimental runs when the impact of plate size on system performance was assessed. This helped ensure that all system electrical demands were satisfied and the power source was not limiting the rate of reaction.

\section{Current Dosage Monitoring and Control System}

Recognizing that a point-of-use EC system could be powered by a rechargeable battery, it was deemed critical to conserve energy while still providing an appropriate level of operational functionality. Accordingly, a small electrical monitoring and dosage control system was designed to measure, record, and display the instantaneous electrical current flow (in milliamps) as well as the totalized current flow (in coulombs). The control system was also designed with a programmable totalized current shut-off set point to discontinue power to the EC system when the set point value for an operating cycle was reached. The shut-off set point value could be programmed into the system based on volume of water to be treated per operating cycle together with the charge dosage needed to the achieve target treated water arsenic level. This approach allowed the system to provide the target charge dosage each cycle even with small variations in electrical current flow due to changes in aqueous phase conductivity or anode/cathode spacing. An actual point-of use system would probably be supplied with the same base controller and an LED "reaction cycle complete" indicator bulb rather than the digital display to reduce costs.

The control system was built around a Texas Instruments model MSP430FR5969 programmable microcontroller. Output readings were directed to a $3.4 \mathrm{~cm}$ (diagonal) Sharp Memory LCD display. A Texas Instruments INA219B integrated circuit was used to monitor electrical current flow to the EC system. A standard USB port provided access to the secondary on-board microcontroller that was used to program the controller and make any necessary runtime adjustments. The cumulative electrical current shut-off set point value could only be changed only by an individual having the required computer resources. A small pushbutton was used to initiate system operation. Once the EC reactor was filled with untreated water and the "start cycle" pushbutton was pressed, no operator attention was required until the designated charge dosage was applied and power delivery to the system was interrupted. A separate pushbutton was provided to reset the control system to allow the next operating cycle to begin once the EC reactor was again filled with untreated water for the next (batch) operating cycle. 
All system components were selected for their low power consumption. The fully configured control module had dimensions of less than $6 \mathrm{~cm} \mathrm{x} 6 \mathrm{~cm} \times 6 \mathrm{~cm}$ and a mass less than $0.25 \mathrm{~kg}$.

\section{Granular Media Filter}

Two granular media filter systems with alternative underdrain systems were assessed for their performance and usability. The first underdrain system utilized perforated PVC piping and a gravel layer below the silica sand media. The second underdrain system consisted of a single ORTHOS Liquid Systems model GVUTM filter nozzle. Each filter made use of an $18.9 \mathrm{~L}$ plastic bucket filled approximately two-thirds to the top with sand. This yielded an effective granular media depth of $0.18 \mathrm{~m}$ for the piped underdrain system and $0.25 \mathrm{~m}$ for the nozzle-based system. The silica sand utilized had an effective size of $0.38 \mathrm{~mm}$ and a uniformity coefficient of 1.35 . A perforated plastic screen was placed just above the top of the granular media to help distribute the flow across the entire filter area. The granular media filter was placed into operation at the end of a reaction cycle in the $\mathrm{EC}$ reactor by manually opening a valve that allowed treated water to flow from the EC reactor to the filter bucket by gravity. Filtered water was discharged through the bottom of the bucket through a hole and fitting arrangement specifically designed to work with each underdrain system. The system outlet discharged into a treated water storage reservoir. Larger, deeper filters were not considered due to their excessive weight.

\section{Synthetic Groundwater}

A synthetic groundwater feed stream was used to minimize any variations in composition that could potentially impact observed system performance. The influent feed was synthesized using reagent grade raw materials and yielded the composition detailed in Table 1.

TABLE 1

MAJOR SYNTHETIC GROUNDWATER COMPONENTS

\begin{tabular}{|c|c|c|}
\hline Constituent & Value/Magnitude & Concentration Units \\
\hline Arsenic & 100,200, or 300 & $\mu \mathrm{g} / \mathrm{L}$ \\
\hline Calcium & 165 & $\mathrm{mg} / \mathrm{L}$ \\
\hline Magnesium & 36 & $\mathrm{mg} / \mathrm{L}$ \\
\hline Sodium & 110 & $\mathrm{mg} / \mathrm{L}$ \\
\hline Bicarbonate & 295 & $\mathrm{mg} / \mathrm{L}$ \\
\hline Phosphorus (as $\left.\mathrm{PO}_{4}{ }^{-}\right)$ & 1.5 & $\mathrm{mg} / \mathrm{L}$ \\
\hline Chloride & 285 & $\mathrm{mg} / \mathrm{L}$ \\
\hline Sulfate & 136 & $\mathrm{mg} / \mathrm{L}$ \\
\hline
\end{tabular}

Small stock solution volumes were added to $1.0 \mathrm{~L}$ of tap water and enough distilled water to produce the final 13.0 L volume used for each test cycle. Arsenic was added as sodium arsenate 
International Journal for Service Learning in Engineering, Humanitarian Engineering and Social Entrepreneurship

Vol. 11, No. 1, pp. 51-66, Spring 2016

ISSN 1555-9033

so that all influent arsenic was in the plus-five $\{\mathrm{As}(\mathrm{V})\}$ oxidation state. No arsenite $\{\mathrm{As}(\mathrm{III})\}$ was included in the synthetic groundwater as it would have been effectively oxidized to arsenate $\{\mathrm{As}(\mathrm{V})\}$ under the conditions realized ${ }^{16}$. The tap water was used to provide trace amounts of any ions that were not added with the stock solutions. Annual water quality reports from the local tap water purveyor indicated that arsenic, iron, and phosphorus contributions from this source were negligible. The $\mathrm{pH}$ of this untreated feed water was 7.8 when measured with a Fisher Scientific Accumet AB15 Plus $\mathrm{pH}$ meter and combination electrode. The solution $\mathrm{pH}$ in the EC module was observed to remain fairly constant $(\Delta \mathrm{pH}<0.1 \mathrm{pH}$ unit) during each treatment cycle. All experimental test runs were conducted at a room temperature of $22 \pm 1{ }^{\circ} \mathrm{C}$.

\section{Analytical Methodology}

Arsenic concentrations were measured using a colorimetric technique demonstrated to have a low detection limit ${ }^{17}$. This method was chosen for its ability to provide accurate results at low arsenic concentration and its low susceptibility to potentially interfering agents. Prepared samples were analyzed using a Shimadzu UVmini-1240 single beam spectrophotometer. Conditions realized during sample preparation ensured that any arsenic in a solid phase would be quickly solubilized. Samples taken during mid-cycle operation of the EC reactor were first filtered using a $0.2 \mu \mathrm{m}$ (pore size) membrane filter and associated vacuum filtration apparatus. Aliquots of the filtered material were then tested colorimetrically after addition of color-inducing reagents. The volume of actual filtered sample used for testing was adjusted as part of the initial sample dilution procedure inherent in the method to provide a fairly consistent mass of arsenic in the final diluted sample. This approach yielded consistent and accurate results when known, standard arsenic solutions were evaluated. Samples collected after granular media treatment were tested both with and without membrane filter pre-filtration. The parallel samples were employed to explore the degree to which relatively small HFO particles were able to pass through the granular filter media material and end up contributing to arsenic levels in the treated water. Arsenic concentrations determined in samples tested after membrane pre-filtration are identified as soluble arsenic concentrations in this study. As an added quality control measure, a number of membrane-filtered samples were split and tested colorimetrically and also using a novel sensor-based technology currently under development ${ }^{18}$. The sensor-based arsenic measurement system is being developed to quickly and reliably measure low levels of arsenic directly in the field and has yielded consistent results with mass spectrometry-based testing at low arsenic concentrations. In this study, the colorimetrically-derived concentrations were found to correlate well with the corresponding sensor-derived values.

\section{RESUlTS AND DiSCUSSION}

\section{Experimental Overview}

Experimentation was divided into three phases as detailed in Table 1. The Preliminary Assessment Phase (Phase 1) was used to identify an EC module configuration that would satisfactorily address all system design and performance constraints. Phase II, System Performance Assessment, examined how performance changed over time and how performance was impacted by different initial arsenic concentrations. Phase III, Filtration Assessment, investigated several potential underdrain systems. There was a limited amount of overlap in Phases II and III where the test runs revolved around a $300 \mu \mathrm{g} / \mathrm{L}$ initial arsenic concentration. 
TABLE 2

EXPERIMENTAL PHASES

\begin{tabular}{|c|c|c|}
\hline $\begin{array}{c}\text { Test } \\
\text { Phase }\end{array}$ & $\begin{array}{c}\text { Number of Experimental } \\
\text { Runs in Indicated Test Phase }\end{array}$ & Experimental Variable(s) Examined \\
\hline I & 14 (some runs terminated early) & $\begin{array}{c}\text { EC plate size } \\
\text { EC plate spacing }\end{array}$ \\
\hline II & 16 & $\begin{array}{c}\text { EC module performance over time } \\
\text { initial arsenic concentration } \\
\text { supplemental external mixing }\end{array}$ \\
\hline III & 12 & filter (underdrain) configuration \\
\hline
\end{tabular}

Phase I testing evaluated the impact of EC module plate size and plate spacing on system operation. In accordance with the results of others ${ }^{15,16}$, the goal during this test cycle was to identify a module configuration that would provide (a) a batch reaction cycle time of less than 60 minutes, (b) a charge dosage rate of no more than 6 coulombs per liter per minute $(\mathrm{C} / \mathrm{L} / \mathrm{min})$, (c) a cumulative charge dosage of no more than 180 coulombs per liter $(\mathrm{C} / \mathrm{L})$ for an initial $300 \mu \mathrm{g} / \mathrm{L}$ arsenic concentration, and (d) dimensional compatibility with the chosen EC reactor vessel. A number of test runs were terminated early when it became apparent that the tested plate spacing would not be able to provide satisfactory operation. The plate spacing coming closest to satisfying all target operating constraints was $22.0 \mathrm{~mm}$ for both plate sizes. A summary of the final (best) operating conditions and general performance results for the two EC modules is included as Table 3.

TABLE 3

SUMMARY OF TEST PHASE I FINAL OPERATING AND PERFORMANCE CHARACTERISTICS

\begin{tabular}{|c|c|c|c|c|}
\hline $\begin{array}{c}\text { EC Module } \\
\text { Plate Size } \\
(\mathbf{m m} \times \mathbf{~ m m})\end{array}$ & $\begin{array}{c}\text { System } \\
\text { Charge } \\
\text { Dosage Rate } \\
(\mathbf{C} / \mathbf{L} / \mathbf{m i n})\end{array}$ & $\begin{array}{c}\text { Charge Dosage to } \\
\text { Reach 10 } \mu \text { g/L As(V) } \\
\text { Concentration }(\mathbf{C} / \mathbf{L})\end{array}$ & $\begin{array}{c}\boldsymbol{\tau}_{10} \text { : Batch Reaction } \\
\text { Time Needed to Reach } \\
\mathbf{1 0} \boldsymbol{\mu g} / \mathbf{L} \text { Soluble As (V) } \\
\text { Concentration (min) }\end{array}$ & Notes \\
\hline $10 \times 10$ & 2.9 & 175 & 60 & $\begin{array}{c}\text { satisfactory } \\
\text { performance }\end{array}$ \\
\hline $15 \times 15$ & 9.1 & 220 & 24 & $\begin{array}{c}\text { plate spacing limited } \\
\text { by bucket size }\end{array}$ \\
\hline
\end{tabular}

The following sections provide additional details on all three experimental phases.

\section{General Observations}

Electrical current flow and associated oxidation-reduction reactions commenced immediately after all electrical connections were completed and power was directed to the EC module. These reactions were characterized by the formation of rust-colored suspended HFO particles and the generation of a continuous stream of fine gas bubbles emanating from the surfaces of the designated cathode plates. Figure 2 shows the progression of HFO precipitate formation during 
the beginning phases of a typical test run with the smaller sized steel plate-based EC module.

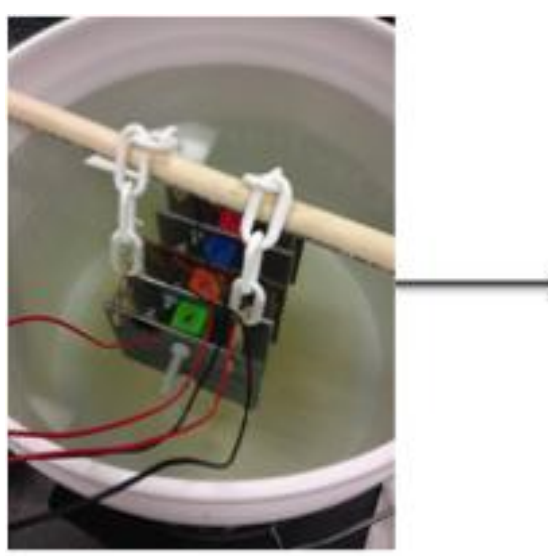

$5 \mathrm{~min}$.

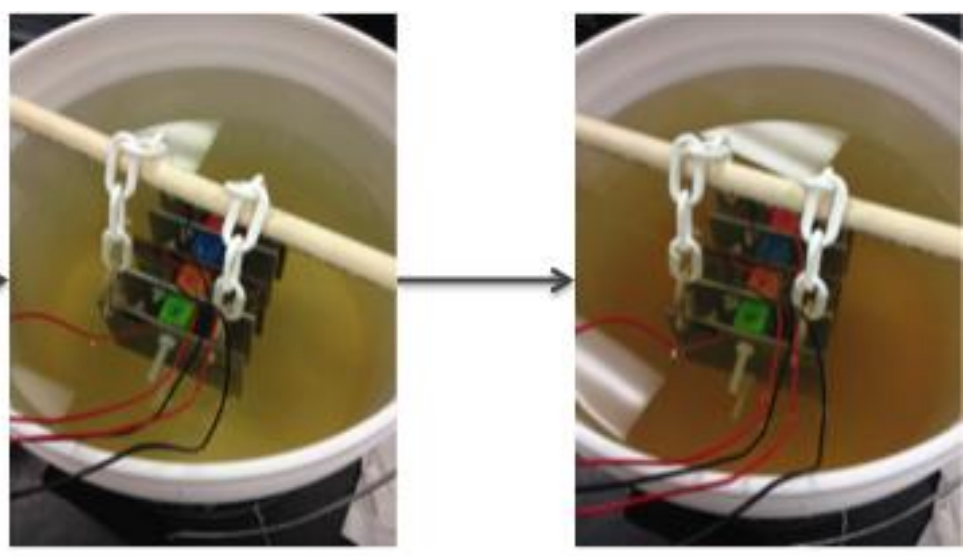

$10 \mathrm{~min}$.
$20 \mathrm{~min}$.

Figure 2

PROGRESSION OF HFO PRECIPITATE FORMATION DURING A TYPICAL TEST RUN

By the end of an operating cycle, the suspended HFO particles in the reactor were distributed from the top to the bottom of the water column in the bucket/reactor. Each of three anode plates became uniformly coated with a rust-colored iron oxide after several successive testing cycles. The two cathode plates remained free of any apparent oxidation and could be used later as anode plates once the companion anode plates reached a point where the extent of the induced oxidation reactions and the associated reduction in structural integrity rendered them unsuitable for continued operation. Gas production from the cathode plates was sufficient to provide a limited degree of liquid mixing in the reaction vessel although larger, heavier HFO particles tended to settle to the bottom portion of the reactor with time. Electrical current draw remained essentially constant during each individual test cycle. The aforementioned rust-like coating on the anode plates thus had little apparent effect on system electrical performance.

\section{Impact of Plate Size}

Arsenic removal patterns observed when using $10 \mathrm{~cm} \times 10 \mathrm{~cm}$ and $15 \mathrm{~cm} \times 15 \mathrm{~cm}$ steel plates as part of the EC module for a typical operating cycle with the aforementioned final plate spacing were investigated to determine how plate size impacted system operating requirements. Current draw for the EC module configured with the smaller sized plates was approximately $0.63 \mathrm{amps}$ while the current draw for the module configured with the larger plates with the same plate spacing was approximately 2.0 amps. The reaction times needed to reduce an initial $300 \mu \mathrm{g} / \mathrm{L}$ arsenic concentration to sub-10 $\mu \mathrm{g} / \mathrm{L}$ levels for the larger and smaller EC module plates were 24 minutes and 60 minutes, respectively. The reduction in reaction/treatment time realized with the larger plates was, however, achieved at a cost of lower overall system electrical efficiency. The cumulative charge dosage needed to produce sub-10 $\mu \mathrm{g} / \mathrm{L}$ soluble arsenic levels increased from about $175 \mathrm{C} / \mathrm{L}$ for the system employing the smaller plates to over $220 \mathrm{C} / \mathrm{L}$ for the system using the larger plates. These trends are consistent with results reported by others ${ }^{15}$. The higher current draw associated with the larger plates, together with the lower electrical efficiency of the 
associated EC module, led to a decision to eliminate use of the $15 \mathrm{~cm} \times 15 \mathrm{~cm}$ plates from further consideration where limitations associated a rechargeable battery power source dictated use of the more efficient system. These initial experiments established baseline performance levels and operational traits for the EC module configured with the $10 \mathrm{~cm} \times 10 \mathrm{~cm}$ plates. For a $300 \mu \mathrm{g} / \mathrm{L}$ initial arsenic concentration, a cumulative charge dosage of $175 \mathrm{C} / \mathrm{L}$ was consistently found to be able to achieve sub- $10 \mu \mathrm{g} / \mathrm{L}$ soluble arsenic levels.

\section{Impact of Anode Condition}

After initial system testing was conducted for characterizing arsenic removal patterns, it became apparent that the arsenic-versus-time removal pattern in the EC reactor changed over time in parallel with the oxidation condition of the anode plates. The first few operating cycles with a newer EC module (little or no apparent surface oxidation on the anodes) was characterized by an exponential decay-type reduction in arsenic concentration with time. As the anode plates became more heavily oxidized after additional operating cycles were completed, a three-phase pattern of soluble arsenic removal was observed. An initial rapid reduction in arsenic concentration was following by a slower, temporary reduction in arsenic removal rate. This was finally followed by a third, faster removal phase with reductions in soluble arsenic concentrations ultimately reaching sub- $10 \mu \mathrm{g} / \mathrm{L}$ levels. This pattern was observed for all "seasoned" anode plates (operated long enough to build up a visible iron oxide coating on the plate surfaces). The differences in arsenic removal patterns when comparing new and "seasoned" EC module anode plates are depicted in Figure 3 for experimental runs conducted with an initial arsenic concentration of $300 \mu \mathrm{g} / \mathrm{L}$.

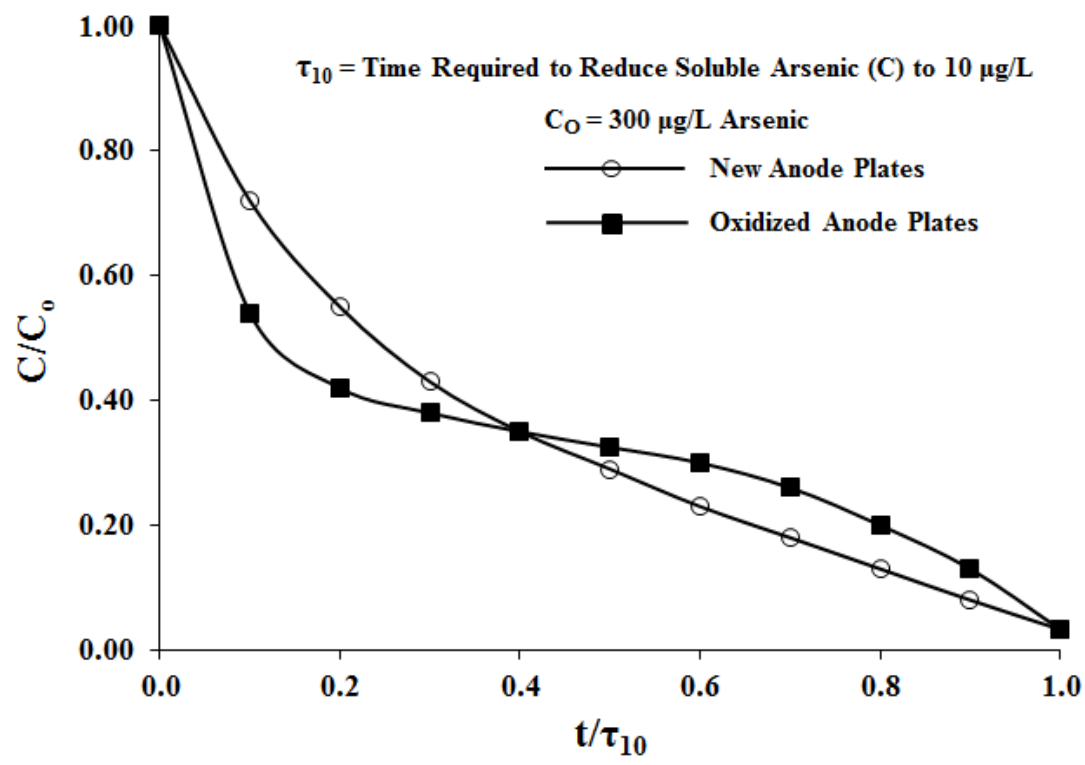

FIGURE 3

IMPACT OF ANODE PLATE OXIDATION STATE ON SOLUBLE ARSENIC REMOVAL PATTERNS.

The first of the three response phases with the seasoned/oxidized anode plates can potentially be related to reports of rapid initial arsenic binding to the oxidized surfaces of EC module anode 
plates $^{10}$. Both the overall batch reaction time ( $\tau_{10}$ in Figure 3$)$ and charge dosage needed to reduce soluble arsenic levels from 300 to $10 \mu \mathrm{g} / \mathrm{L}$ were unaffected by the degree of anode oxidation for a given EC module plate size. This is consistent with observations over the duration of the experimental period that anode oxidation condition had no impact on system current draw and general electrical performance. Required reaction time was independent of plate condition. Test runs conducted with other initial arsenic concentrations all involved the use of "seasoned" plates and were characterized by the aforementioned three-phase response.

\section{Impact of Initial Arsenic Concentration}

Experiments were conducted using initial arsenic concentrations of 100, 200, and $300 \mu \mathrm{g} / \mathrm{L}$. This represented the typical range of arsenic concentrations found in many areas of South Asia. The required cumulative charge dosage required to achieve the sub-10 $\mu \mathrm{g} / \mathrm{L}$ soluble arsenic levels in the treated water were approximately 102,154 , and $175 \mathrm{C} / \mathrm{L}$ for initial arsenic concentrations of 100,200 , and $300 \mu \mathrm{g} / \mathrm{L}$, respectively. The smaller cumulative charge dosages required for treatment with lower initial arsenic concentrations translates into an ability to treat more water with a single charge for a rechargeable battery. Conversely, higher initial arsenic levels would require greater charge dosages. This suggests that an accurate assessment of the untreated water quality would be needed to optimize power usage with the electrical controller.

\section{Impact of Supplemental Mechanical Mixing}

The impact on arsenic removal of providing supplemental mechanical mixing in the EC reactor is shown in Figure 4. Supplemental mechanical mixing did not improve arsenic removal in the test system when compared to the same system operated without any supplemental mixing. The stream of fine bubbles produced from the cathode plates apparently satisfied any mixing needed to allow the generated HOF particles (and/or the exposed anode surfaces) to effectively interact with the solution phase arsenic. The absence for any need for external mixing in this prototype system, however, should not be interpreted to be a universal statement; systems should be evaluated on a case-by-case basis as the dimensions and production capacities for individual systems vary. 


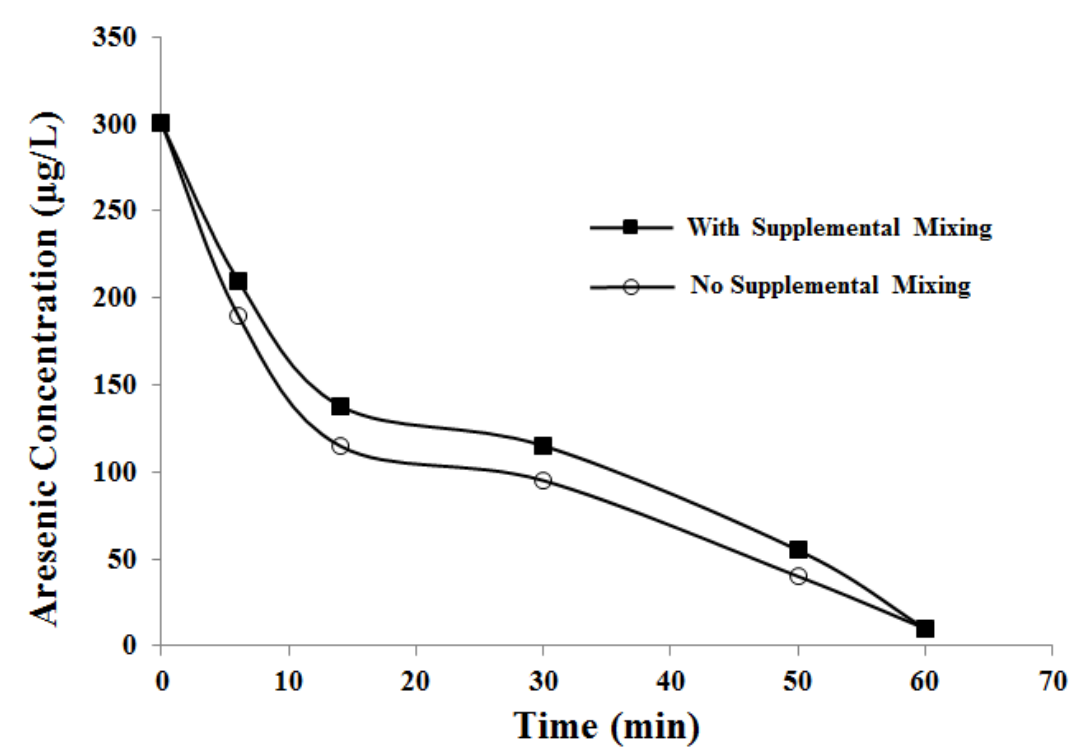

FIGURE 4

IMPACT OF SUPPLEMENTAL MIXING ON SOLUBLE ARSENIC REMOVAL.

\section{Filtration Effectiveness}

The filter system employing the nozzle-based underdrain system was quickly chosen over the PVC pipe and gravel underdrain system because of its relative simplicity and ease/rapidity of media replacement. The ability of the nozzle-based system to remove HFO particles and its associated arsenic was evaluated by comparing arsenic levels in final effluent samples with and without membrane pre-filtration. Particle-laden water from the EC reactor was fed to the filter at a rate of approximately $1.6 \mathrm{~L} / \mathrm{min}$ using a manual control valve (yielding a calculated filter application rate of $37 \mathrm{~m}^{3} / \mathrm{m}^{2} / \mathrm{d}$ ). Direct measurement of arsenic levels in the filter effluent ranged between 9 and $21 \mu \mathrm{g} / \mathrm{L}$ while arsenic concentrations measured in parallel, membrane filtered samples were consistently below $10 \mu \mathrm{g} / \mathrm{L}$. A few HFO particles apparently were able to pass through the granular media filter bed. Alum has been used to help improve HFO particle removal in a larger scale EC system arsenic removal systems ${ }^{14}$. The sub- $10 \mu \mathrm{g} / \mathrm{L}$ arsenic levels achieved after membrane filtration offer hope that an enhanced granular media filter or another size-appropriate solids separation technology can be used to meet global standards.

\section{Practical Operating Considerations}

System operation with the $10 \mathrm{~cm} \times 10 \mathrm{~cm}$ plates and an influent arsenic concentration of 300 $\mu \mathrm{g} / \mathrm{L}$ required approximately 60 minutes to treat $13 \mathrm{~L}$ of water. Including eight minutes to transfer liquid from the EC reactor to the granular media filter, about 9.0 hours would be needed to provide roughly $100 \mathrm{~L}$ of final product water needed daily for a family of five using a WHOrecommended supply rate of $20 \mathrm{~L} /$ capita/d. The $20 \mathrm{~L} /$ capita/d supply rate seems acceptable considering that little arsenic is absorbed directly through the skin $^{19}$ and arsenic containing groundwater can be used for other non-potable purposes. Use of the control system would allow the system owner more discretion over how the system is operated but the total required time 
International Journal for Service Learning in Engineering, Humanitarian Engineering and Social Entrepreneurship Vol. 11, No. 1, pp. 51-66, Spring 2016

ISSN 1555-9033

would remain unchanged. Access to a continuous, centralized power distribution system would potentially allow larger plates to be used in the EC module and reduce treatment times.

While this investigation did not address the potential effect of untreated water $\mathrm{pH}$ on system performance, other studies have specifically examined the impact of $\mathrm{pH}$ on the removal of arsenic by HFO particles in similar systems ${ }^{12,13}$. These investigations have reported that arsenic adsorption onto HFO particles is fairly independent of $\mathrm{pH}$ up to a $\mathrm{pH}$ of 8 . Limited available field data suggest that groundwaters in the Southern Asia area have $\mathrm{pH}$ levels in the near-neutral $\mathrm{pH}$ range ${ }^{6,14}$ and, as seen herein, would provide a suitable aqueous environment for the application of EC technology. These groundwaters also appear to have an ionic composition (and electrical conductivity) that would also support EC-based arsenic removal systems.

A stoichiometric reaction equation describing the production of HFO particles in EC systems has been presented by Ji, et al. ${ }^{13}$ and is shown below as Equation (1).

$$
4 \mathrm{Fe}_{(\mathrm{s})}+10 \mathrm{H}_{2} \mathrm{O}_{(\mathrm{l})}+\mathrm{O}_{2(\mathrm{~g})} \rightarrow 4 \mathrm{Fe}(\mathrm{OH})_{3(\mathrm{~s})}+4 \mathrm{H}_{2(\mathrm{~g})}
$$

Using this reaction and the $175 \mathrm{C} / \mathrm{L}$ charge dosage needed to affect arsenic removal for an initial arsenic concentration of $300 \mu \mathrm{g} / \mathrm{L}$, Faraday's Law suggests that 0.45 liters of hydrogen gas would be produced at standard temperature and pressure during each 60-minute operating cycle. While this is not a particularly large volume of hydrogen, its potential accumulation over time suggests that EC systems be located in a well-ventilated space to avoid any explosive conditions.

The iron anode plates in the system must be considered a consumable material. Again using Faraday's Law, it was estimated that the $10 \mathrm{~cm} \times 10 \mathrm{~cm}$ anode plates would be completely consumed in about 150 days when producing $100 \mathrm{~L} / \mathrm{d}$ of treated water at a charge dosage of 175 $\mathrm{C} / \mathrm{L}$. The actual working life of the plates is probably 80 to 90 percent of this value as the plates would become mechanically unstable before being completely consumed. Sand in the granular media filter must also be considered a consumable material. Suspended solids production rates of 55,100 , and $155 \mathrm{mg} / \mathrm{L}$ were measured after applied charge dosages of 60,120 , and $175 \mathrm{C} / \mathrm{L}$, respectively. With the maximum rate of solids production, sand replacement frequency was estimated to be every three days. A local source for the sand should be available for long-term system operation. Spent sand must be disposed of in a responsible manner. Fortunately, the HFO particle-bound arsenic is highly resistant to leaching ${ }^{15}$ and this will help ensure that once removed, the arsenic can be effectively contained. A dedicated sand disposal pit (no co-disposal with waste organic materials) should be located as far as reasonably possible from any wells.

Table 4 presents projected cost information for a point-of-use arsenic removal system employing EC technology. Useful lives for individual system elements were estimated based on expected field conditions in south Asia for a water production rate of up to $100 \mathrm{~L} / \mathrm{d}$. A discount rate of five percent was used in determining the annual cost. The cost for individual items, in U.S. dollars (USD), reflects quantity discounts and an estimated amortized cost of $\$ 0.12 / \mathrm{kw}-\mathrm{hr}$ (8.0 Indian Rs per kw-hr) for power from a small, modular community-based solar-power system in South Asia. The two oversized batteries identified for use in the EC system include one unit actively powering the system while the second is being recharged. A more robust battery could be used to decrease the recharge frequency but only at substantial additional cost. 
International Journal for Service Learning in Engineering, Humanitarian Engineering and Social Entrepreneurship Vol. 11, No. 1, pp. 51-66, Spring 2016

ISSN 1555-9033

TABLE 4

ESTIMATED ANNUAL COST OF A 100 LITER PER DAY POINT-OF-USE TREATMENT SYSTEM

\begin{tabular}{|c|c|c|c|c|}
\hline Item & $\begin{array}{c}\text { Required } \\
\text { Quantity }\end{array}$ & $\begin{array}{c}\text { Total Estimated } \\
\text { Cost (USD) }\end{array}$ & $\begin{array}{c}\text { Useful Life } \\
\text { (years) }\end{array}$ & $\begin{array}{c}\text { Equivalent Uniform } \\
\text { Annual Cost (USD) }\end{array}$ \\
\hline plastic bucket & 3 & 9.00 & 5 & 2.08 \\
\hline steel plates & $0.75 \mathrm{~kg}$ & 0.40 & 0.33 & 1.21 \\
\hline misc. hardware & lump sum & 6.50 & 5 & 1.50 \\
\hline battery & 2 & 20.00 & 3 & 7.34 \\
\hline filter sand & $0.015 \mathrm{~m}^{3}$ & 0.03 & 0.01 & 3.00 \\
\hline underdrain nozzle & 1 & 4.00 & 5 & 0.92 \\
\hline timer/controller & $1 *$ & $5.00-9.00$ & 5 & $1.15-2.08$ \\
\hline electrical power & $11 \mathrm{kw}-\mathrm{hr} / \mathrm{yr}$ & 1.33 & - & 1.33 \\
\hline
\end{tabular}

Total Equivalent Uniform Annual Cost (USD)

$18.53-19.46$

* the cost of the timer/controller varies depending on the output (LED bulb versus LED screen)

Table 5 presents published cost data for point-of-use arsenic removal technologies. Owing to different locales and system production capacities, direct comparisons of production costs are difficult. In one case, only operating costs were directly reported without any estimation of related amortized (initial and/or recurring) system capital costs. Iron coagulation-based systems, in general, have been identified as one of the most cost effective technologies for small scale arsenic removal when compared to other systems proposed for use in the South Asia region ${ }^{5}$.

TABLE 5

COST DATA FOR POINT-OF-USE ARSENIC TREATMENT SYSTEMS

\begin{tabular}{|c|c|c|c|c|}
\hline Technology & Study Location & Capacity (L/d) & $\operatorname{Cost}\left(\$ / \mathrm{m}^{3}\right)$ & Reference \\
\hline Electrocoagulation & South Asia & 100 & $0.51-0.53$ & this study \\
\hline Iron Salt Coagulation & South Asia & $20+$ & $1.33 *$ & Hwang $^{20}$ \\
\hline Electrocoagulation & South Asia & not reported & $0.83-1.04$ & Amrose, et al. ${ }^{14}$ \\
\hline Adsorption & US & 9.2 & 35.82 & Thomson, et al. ${ }^{21}$ \\
\hline
\end{tabular}

* includes only operating costs

Even the relatively modest costs indicated in Table 5 for point-of-use treatment systems would require financial subsidies for sustained operation in most rural South Asia communities $^{22,23}$. Economies-of-scale realized for communal treatment systems would reduce 
International Journal for Service Learning in Engineering, Humanitarian Engineering and Social Entrepreneurship Vol. 11, No. 1, pp. 51-66, Spring 2016

ISSN 1555-9033

costs, operating subsidies, and user attention requirements ${ }^{24,25}$ but would, in turn, require a suitable population density and a reasonable level of local trust in such centralized operations.

In considering the electrical components needed to fabricate the point-of-use treatment system used in these experiments, the parts and technical expertise required to manufacture the control system is certainly available in the South Asia region. Basic steel plates are also produced in the region at costs lower than many other parts of the world. Future integration of a low-cost arsenic sensor ${ }^{18}$ with the electrical control system could make this type of treatment more cost-effective. The sensor could determine when the arsenic level in the EC reactor have reached a target value and then would direct the controller to discontinue power to the system and alert the system attendant. This approach would optimize the use of consumable iron plates and provide real time response to changes in the composition of the untreated groundwater. While the control system does make EC treatment more complex than other currently promising point-of-use arsenic removal systems ${ }^{26}$, its ability to function when local, available groundwaters contain elevated concentrations of reduced arsenic and/or reduced iron renders it a viable option to consider in situations where long-term operational problems related to poor adsorption or insystem inorganic mineral oxidation and precipitation reactions are likely to occur.

Wide-spread implementation of point-of-use EC treatment systems in rural communities should be conducted under the auspices of an NGO or similar local authority. In this manner, the technical expertise needed for training and system monitoring will be available on an ongoing basis. This expertise would also help ensure that supplies of consumables were available and process residuals were managed properly. The NGO or local authority could also play a role in providing centralized facilities for recharging batteries that would be used as the power source for these systems and then managing battery disposal when they are no longer functional.

\section{CONCLUSIONS AND RECOMMENDATIONS}

Small-scale or point-of-use EC systems are capable of reducing arsenic concentrations down to levels of $20 \mu \mathrm{g} / \mathrm{L}$ or less. If granular media filtration can be cost-effectively enhanced or replaced with a more effective, low-cost technology, treated water arsenic concentrations below $10 \mu \mathrm{g} / \mathrm{L}$ can be reliably achieved. Point-of-use EC treatment systems can be powered by small, rechargeable batteries with the ability to produce up to $100 \mathrm{~L}$ of water on a single charge. Supplemental mixing appears to have little impact on system performance in a bucket-scale operation. The prototype system tested made use of an innovative electrical control system to efficiently use available power and minimize iron consumption. A discharge nozzle-based filtration unit was developed to simplified media replacement. Developing arsenic sensor technologies could also be used to optimize system performance. In designing EC systems, compromises will have to be made between treated water productivity rate and energy efficiency; decreases in processing time may likely come at higher electrical consumption per unit volume of water produced. No attempt was made to assess the disinfection needs of an ECbased treatment systems. This should be an area of future research. Lastly, assistance provided by an NGO or governmental entity is key to the successful field implementation of this technology. Based on observations with other point-of-use arsenic mitigation systems, this assistance would probably need to include both technical oversight and financial subsidies. 
International Journal for Service Learning in Engineering, Humanitarian Engineering and Social Entrepreneurship

Vol. 11, No. 1, pp. 51-66, Spring 2016

ISSN 1555-9033

\section{ACKNOWLEDGEMENTS}

The authors would like to acknowledge the input of David Sowerwine of VillageTech Solutions in identifying key design and operating criteria and constraints for the prototype system as well as the Santa Clara University Miller Center for Social Entrepreneurship and its Roelandts Grant Program for its financial support of the investigation.

\section{REFERENCES}

1. Ravenscroft, P., H. Brammer and K. Richards, Arsenic pollution: a global synthesis. 2009. Wiley-Blackwell, West Sussex, UK.

2. Murcott, S., Arsenic contamination in the world: an international sourcebook. 2012. International Water Association, London, UK.

3. Yoshida. T., H. Yamauchi and G.F. Sun, Chronic health effects in people exposed to arsenic via the drinking water: dose-response relationships in review. Toxicol. Appl. Pharma., 2004. 198(3): p. 243-252.

4. Mudhoo, A., S.J. Sharma, V.K. Garg and C-H Tseng, Arsenic: an overview of applications, health, and environmental concerns and removal processes. Crit. Rev. Environ. Sci. Technol., 2011. 41(5): p. 435-519.

5. Johnston, R. and H. Heijnen, Safe water technology for arsenic removal. In Technologies for arsenic removal from drinking water, 2001. M.F. Ahmed, M.A. Ali, and Z. Adeel (eds.), Bangladesh University of Engineering and Technology. p. 1-22.

6. Sutherland, D., P.M. Swash, A.C. Macqueen, L.E. McWilliam, D.J. Ross and S.C. Wood, $A$ field based evaluation of household arsenic removal technologies for the treatment of drinking water. Environ. Tech., 2002. 23(12): p. 1385-1404.

7. Garelick, H., A. Dybowska, E. Valsami-Jones and N.D Priest, Remediation technologies for arsenic contaminated drinking waters. J. Soils \& Sediments, 2005. 5(3): p. 182-190.

8. Petrusevski, B., S. Sharma, W.G. van der Meer, F. Kruis, M. Khan, M. Barua and J.C. Schippers, Four years of development and field-testing of IHE arsenic removal family filter in rural Bangladesh. Water Sci. \& Tech, 2008. 58(1): p. 53-58.

9. Duarte, A., S. Cardoso and A. Alcada, A., Emerging and innovative techniques for arsenic removal applied to a small water supply system. Sustainability, 2009. 1(4): p. 1288-1304.

10. Lakshmanan, D., D.A. Clifford and G. Samanta, Comparative study of arsenic removal by iron using electrocoagulation and chemical coagulation. Water Research, 2010. 44(19): p. 5641-5652.

11. Wan, W., T.J. Pepping, T. Banerji, S. Chaudhari and D.E. Giammar, Effects of water chemistry on arsenic removal from drinking water by electrocoagulation. Water Research, 2011. 45(1): p. 384-392.

12. Kumar, P. R., S. Chaudhari, K.C. Khilar and S.P. Mahajan, Removal of arsenic from water by electrocoagulation. Chemosphere, 2004. 55(9): p. 1245-1252.

13. Ji, S., B.A. Dempsey and K. Yoo, The removal of arsenic ion in electro-coagulation cell. Geosys. Eng., 2011. 14(2): p. 71-78.

14. Amrose, S.E., S.R.S. Bandaru, C. Delaire, C. van Genuchten, A. Dutta, A. DebSarker, C. Orr, J. Roy, A. Das, A. and A.J. Gadgil, Electro-chemical arsenic remediation: field trials in West Bengal. Sci. Total Environ. 2014. 488-489: p 539-546. 
15. Amrose, S.E., A. Gadgil, V. Srinivasan, K. Kowolik, M. Muller, J. Huang and R. Kostecki, Arsenic removal from groundwater using iron electrocoagulation: effect of charge dosage rate. J. Environ. Sci. Health, Pt. A: Toxic/Hazard. Substan. Environ. Eng., 2013. 48(9): p. 1019-1030.

16. Li, L., C. van Genuchten, S. Addy, J. Yao, N. Gao and A. Gadgil, Modeling As(III) oxidation and removal with iron electrocoagulation in groundwater. Environ. Sci. Technol., 2012. 46: p. 12038-12045.

17. Agrawal, O., G. Sunita, and V.K. Gupta, A sensitive colorimetric method for the determination of arsenic in environmental and biological samples. J. Chin. Chem. Soc., 1999. 46(4): p. 641-645.

18. Kim, U., J. VanderGiessen, J. and X. Savarimuthu, Implementation of electrochemical sensors in arsenic-contaminated areas of West Bengal in India toward rapid and point-of-use detection of arsenic in drinking water, Proceedings of the IEEE global humanitarian technology conference, 2014. p. 474-478.

19. ATSDR (U.S. Department of Health and Human Services), Public health statement: arsenic CAS\#: 7440-38-2. 2007. Available from www.atsdr.cdc.gov/ToxProfiles/tp2-c1-b.pdf.

20. Hwang, S.K., Point-of-use arsenic removal from drinking water in Nepal using coagulation and filtration, M.S. Thesis, Massachusetts Institute of Technology, 2002. Available from web.mit.edu/watsan/Docs/Student\%20Theses/Nepal/Hwang2002.pdf.

21. Thomson, B.M., T.J. Cotter and J.D. Chwirka, Design and operation of point-of-use treatment system for arsenic removal. J. Environ. Eng., 2003. 129(6): p. 561-564.

22. Hoque, B.A., A.A Mahmood, M. Quadiruzzaman, F. Khan, S.A. Ahmed, S. Shafique, M. Rahman, G. Moshed, T. Chowdhury, M.M. Rahman, M. Shahjahan and M.M. Hoque, 2000 Recommendations for water supply in arsenic mitigation: a case study from Bangladesh. Public Health, 2000. 114(6): p. 488-494.

23. Hassan, M., P. Atkins and C. Dunn, Suitable arsenic mitigation options in Bangladesh: voices of local people. Indian J. Landscape Sys. \& Ecol. Stud., 2004. 27(2): p. 1-7.

24. Hoque, B.A., M.M. Hoque, T. Ahmed, S. Islam, A.K. Azad, N. Ali, M. Hossain and M.S. Hossain, Demand-based water options for arsenic mitigation: an experience from rural Bangladesh. Public Health, 2004. 118(1): p. 70-77.

25. Malik, A.H., Z.M. Khan, Q. Mahmood, S. Nasreen, S. and Z.A. Bhatti, Perspectives of lowcost arsenic remediation of drinking water in Pakistan and other countries. J. Haz. Materials, 2009. 168(1): p. 1-12.

26. Passman, S.D., T.J. White and R.D. Lewis, Point-of-use water filtration for arsenic: $a$ sustainable and simple solution in resource-poor settings. Intl. J. Service Learning Engr., 2014. 9(1): p. 79-91. 